\title{
FAKTOR AKTIVITAS FISIK TERHADAP STATUS GIZI SISWA DI SMA NEGERI 2 KOTA PALANGKA RAYA
}

\author{
*Andi Tenri Abeng \\ Jurusan Pendidikan Jasmani, Kesehatan, dan Rekreasi, FKIP Universitas Palangka Raya \\ Correspondence author: anditenriabeng@ fkip.upr.ac.id, Palangkaraya, Indonesia
}

DOI: https://doi.org/10.37012/jik.v12i1.147

\begin{abstract}
ABSTRAK
Masalah gizi pada dasarnya merupakan refleksi konsumsi zat gizi yang belum mencukupi kebutuhan tubuh. Gizi remaja perlu mendapat perhatian karena mempengaruhi pertumbuhan dan perkembangan tubuh, serta dampaknya pada masalah gizi dewasa. Tujuan penelitian ini adalah untuk mengetahui pengaruh faktor aktivitas fisik terhadap status gizi siswa di SMA Negeri 2 Kota Palangka Raya. Penelitian ini merupakan penelitian kuantitatif dengan subjek penelitian adalah siswa kelas 2 SMA Negeri 2 Kota Palangka Raya sebanyak 112 responden. Instrumen penelitian menggunakan kuesioner untuk mengetahui aktivitas fisik siswa dan melakukan pengukuran tinggi dan berat badan untuk mengetahui status gizi siswa. Data dianalisis secara univariat dan bivariat. Analisis data univariat jenis kelamin, laki-laki sebanyak 52 responden $(46,43 \%)$ dan perempuan sebanyak 60 responden $(53,57 \%)$. Data pekerjaan orang tua responden paling banyak adalah PNS $31,25 \%$, jarak rumah ke sekolah responden paling banyak adalah 3 - $5 \mathrm{Km}(38,39 \%)$, aktivitas fisik responden terbanyak pada aktivitas sedang $(66,96 \%)$, dan status gizi responden paling banyak adalah normal $(58,93 \%)$. Analisis bivariat untuk mengetahui pengaruh aktivitas fisik terhadap status gizi menggunakan Uji Chi-Square dan diperoleh nilai $\mathrm{P}$ value 0,002 dengan nilai $\mathrm{OR} 3,71$ (CI 1,63-8,48). Ini bermakna bahwa memiliki aktivitas fisik yang kurang baik berisiko status gizi yang tidak normal sebesar 3,71 kali dibanding memiliki aktivitas disik yang baik. Disimpulkan bahwa faktor aktivitas fisik mempengaruhi status gizi siswa di SMA Negeri 2 Palangka Raya.
\end{abstract}

Kata kunci: Aktivitas Fisik, Status Gizi.

\begin{abstract}
Nutrition problems are basically a reflection of the consumption of nutrients that are not sufficient for the body's needs. Adolescent nutrition needs attention because it affects the growth and development of the body, and its impact on adult nutrition problems. The purpose of this study was to determine the effect of physical activity factors on the nutritional status of students in SMA Negeri 2 Palangkaraya City. This research is a quantitative study with the subject of the research is the students of class 2 of SMA Negeri 2 Palangka Raya City as many as 112 respondents.

The research instrument used a questionnaire to determine student physical activity and to measure height and weight to determine the nutritional status of students. Data were analyzed univariately and bivariately. Univariate analysis of sex data, men as many as 52 respondents (46.43\%) and women as many as 60 respondents (53.57\%). Most respondents 'occupational data were 31.25\% civil servants, the most distance from the respondent's house to school was 3-5 Km (38.39\%), most respondents' physical activity was moderate $(66.96 \%)$, and nutritional status most respondents were normal (58.93\%).Bivariate analysis to determine the effect of physical activity on nutritional status using the Chi-Square Test and P value of 0.002 was obtained with an OR value of 3.71 (CI 1.63-8.48). This means that having poor physical activity risks an abnormal nutritional status of 3.71 times compared to having good physical activity. It was concluded that physical activity factors influence the nutritional status of students in SMA Negeri 2 Palangka Raya.
\end{abstract}

Keywords: Physical Activity, Nutrition Status. 


\section{PENDAHULUAN}

Masalah gizi pada remaja menjadi perhatian karena mempengaruhi pertumbuhan dan perkembangan tubuh dan berdampak pada masalah gizi dewasa (Pudjiadi, 2005). Anak akan mengalami perubahan fisik, psikologi dan pola identifikasi mejadi dewasa. Ini ditandai dengan pertumbuhan tubuh dan pematangan organ reproduksi.

Perubahan tersebut dapat menimbulkan masalah dan perilaku remaja, seperti perubahan perilaku makan baik mengarah keperilaku makanan yang sehat atau cenderung mengarah perilaku makan yang tidak sehat. Status gizi adalah suatu ukuran mengenai kondisi tubuh seseorang yang dapat dilihat dari makanan yang dikonsumsi dan penggunaan zat-zat gizi di dalam tubuh. Ini dipengaruhi beberapa faktor yaitu faktor lingkungan, faktor sosial ekonomi, faktor kognitif, faktor biologis, faktor gaya hidup, dan status kesehatan (Proverawati, 2010).

Keadaan sehat akan memungkinkan setiap orang hidup sejahtera, oleh karena itu, kesehatan harus diwujudkan untuk martabat manusia. Ini berdasarkan UU no. 36 tahun 2009 tentang Kesehatan, yang dimaksud kesehatan adalah keadaan sehat, baik secara fisik, mental, spiritual maupun sosial yang memungkinkan setiap orang untuk hidup produktif secara sosial dan ekonomis (Almatsier, 2004). Tingkat kesehatan dipengaruhi beberapa faktor yaitu bebas dari penyakit atau cacat, keadaan sosial ekonomi yang baik, keadaan lingkungan yang baik, dan status gizi juga baik (Arisman, 2009).

Status gizi yang baik tidak mudah terkena penyakit dan salah satu faktor penting dalam mencapai derajat kesehatan yang optimal. Tetapi di masyarakat masih ditemukan penyakit karena kekurangan gizi. Masalah gizi merupakan refleksi konsumsi zat gizi yang belum mencukupi kebutuhan tubuh (Proverawati, 2010). Asupan gizi yang kurang dapat menyebabkan kekurangan gizi. Status gizi merupakan gambaran individu sebagai akibat dari asupan gizi sehari-hari dan dapat diketahui melalui pengukuran beberapa parameter, lalu dibandingkan dengan standar atau rujukan. Dengan diketahui status gizi, dapat dilakukan upaya untuk memperbaiki tingkat kesehatan pada masyarakat (Kuriman, 2011).

Aktivitas fisik merupakan pergerakan tubuh yang menyebabkan pengeluaran tenaga (pembakaran kalori), yang meliputi aktivitas fisik sehari-hari- dan olahraga, sedangkan menurut WHO (2010) merupakan kegiatan yang paling sedikit 10 menit tanpa henti. 
Dampak negatif rendahmya aktivitas fisik yaitu meningkatkan risiko penyakit kronis, gangguan metabolik, penurunan kesehatan mental,

performa fisik dan gangguan kekuatan tulang dan otot (Adityawarman, 2007).

Sudah banyak memberlakukan 5 hari sekolah di Kota Palangka Raya, seperti pada SMA Negeri 2 Kota Palangka Raya. Sekolah ini merupakan salah satu sekolah terfavorit di Kota Palangka Raya. Tiap angkatan terdapat 13 kelas dengan rata-rata jumlah murid 40 siswa. Dengan padatnya kegiatan belajar, peneliti berminat untuk meneliti status gizi siswa pada SMA Negeri 2 Kota Palangka Raya dengan judul "Faktor Aktivitas Fisik terhadap Status Gizi Siswa di SMA Negeri 2 Kota Palangka Raya”.

\section{METODE}

Penelitian ini dengan pendekatan cross sectional study. Penelitian dilakukan di SMA Negeri 2 Palangka Raya. Pengambilan data pada bulan Juli 2018. Populasi penelitian adalah siswa kelas XI SMA Negeri 2 Palangka Raya sebanyak 520 siswa, dan besar sampel penelitian adalah 112 responden dengan sistem random sampling.

Teknik pengumpulan data dengan melakukan pengukuran antropometri, yaitu tinggi badan dan berat badan lalu dikonversi di tabel Standar Antropometri Penilaian Status Gizi Anak (Kemenkes RI, 2011). Dan untuk aktivitas fisik menggunakan kuesioner. Kemudian dianalisis secara univariat dan bivariat. Analisis univariat dilakukan untuk mengetahui secara deskriptif terhadap responden dan analisis bivariat dilakukan menganalisis hubungan antar dua variabel (Notoatmodjo, 2010 dan Sugiyono, 2007), yaitu faktor aktivitas fisik dan status gizi siswa.

\section{HASIL DAN PEMBAHASAN}

\section{Hasil}

\section{Analisis Univariat}

Analisis dilakukan untuk mendistribusikan berdasarkan variabel penelitian, yang bertujuan untuk mengetahui sebaran frekuensi responden pada tabel 1.

Berdasarkan tabel 1 menunjukkan bahwa untuk paling banyak berjenis kelamin laki-laki sebanyak 60 responden $(53,57 \%)$. Pekerjaan orang tua responden paling banyak adalah 
PNS sebanyak 35 responden $(31,25 \%)$. Berdasarkan jarak rumah ke sekolah, paling banyak sekitar 3-5 km sebanyak 43 responden (38,39\%). Untuk aktivitas fisik paling banyak beraktivitas sedang sebanyak 75 responden $(66,96 \%)$ dan paling banyak berstatus gizi normal sebanyak 66 responden $(58,93 \%)$.

Tabel 1. Distribusi Identitas Responden

\begin{tabular}{lcc}
\hline \multicolumn{1}{c}{ Variabel } & Frekuensi & Persen (\%) \\
\hline Jenis Kelamin & 52 & 46,43 \\
Laki-laki & 60 & 53,57 \\
Perempuan & & \\
\hline Pekerjaan Orang Tua & 35 & 31,25 \\
PNS & 33 & 29,46 \\
Pedagang & 8 & 7,14 \\
Karyawan Swasta & 9 & 8,04 \\
Buruh & 14 & 12,50 \\
Petani & 13 & 11,61 \\
Lain-lain & & \\
\hline Jarak Rumah ke Sekolah & 10 & 8,93 \\
< 1 Km & 22 & 19,64 \\
1 - 3 Km & 43 & 38,39 \\
3 - 5 Km & 37 & 33,04 \\
$>$ 5 Km & & \\
\hline Aktivitas Fisik & 22 & 19,64 \\
Ringan & 75 & 66,96 \\
Sedang & 15 & 13,39 \\
Berat & & \\
\hline Status Gizi & 5 & 4,46 \\
Sangat Kurus & 16 & 14,29 \\
Kurus & 66 & 58,93 \\
Normal & 17 & 15,14 \\
Gemuk & 8 & \\
Obesitas & & \\
\hline Sumber: Data Primer 2018 & \\
\hline
\end{tabular}

\section{Analisis Bivariat}

Tabel 2. Distribusi Faktor Aktivitas Fisik terhadap Status Gizi Siswa di SMA Negeri 2 Palangka Raya

\begin{tabular}{lccc}
\hline \multicolumn{1}{c}{ Variabel } & \multicolumn{2}{c}{ Status Gizi } & Total \\
\cline { 2 - 3 } & Normal (\%) & Tidak Normal (\%) & $75(100)$ \\
Aktivitas Fisik & $52(69,33)$ & $23(30,67)$ & $37(100)$ \\
Kurang Baik (\%) & $14(37,84)$ & $23(62,16)$ & $112(100)$ \\
\hline Total & $66(58,93)$ & $46(41,07)$ & \\
\hline
\end{tabular}

Sumber: Data Primer, 2018 
Analisis dilakukan untuk mengetahui hubungan antar dua variabel, yaitu aktivitas fisik dan status gizi siswa. Untuk kategori aktivitas fisik menjadi baik dan kurang baik, sedangkan kategori status gizi menjadi normal dan tidak normal, ini yang dapat dilihat pada tabel 2 .

Tabel 3. Analisis Faktor Aktivitas Fisik terhadap Status Gizi Siswa di SMA Negeri 2 Palangka Raya

\begin{tabular}{lcccc}
\hline \multicolumn{1}{c}{ Analisis } & OR & P value & $\boldsymbol{\alpha}$ & Conf. Interval \\
\hline $\begin{array}{l}\text { Faktor Aktivitas Fisik terhadap } \\
\text { Status Gizi Siswa }\end{array}$ & 3,71 & 0.002 & 0,05 & $1,63-8,48$ \\
\hline
\end{tabular}

Berdasarkan tabel 3, hasil analisis regresi logistic menunjukkan nilai Pvalue 0,002 yang berarti bahwa faktor aktivitas fisik mempengaruhi status gizi remaja di SMA Negeri 2 Kota Palangka Raya. Untuk nilai OR (odds ratio) diperoleh 3,71 dengan CI 1,63 - 8,48. Ini bermakna bahwa dengan memiliki aktivitas fisik yang kurang baik berisiko 3,71 kali mengalami status gizi yang tidak normal dibandingkan memiliki aktivitas fisik yang baik.

\section{Pembahasan}

Usia remaja jika telah mencapai usia 10-18 tahun untuk anak perempuan dan 12-20 tahun untuk anak laki-laki. Pada usia ini terjadi perubahan fisik yang sangat cepat yang akan mempengaruhi status kesehatan dan gizi anak. Anak perempuan pertumbuhannya lebih cepat daripada anak laki-laki (Sulistyoningsih, 2012). Usia remaja mengalami masa pertumbuhan sehingga kebutuhan gizi remaja relatif besar. Di usia tersebut, aktivitas fisik lebih tinggi dibandingkan dengan usia lainnya, sehingga diperlukan asupan gizi yang lebih banyak (Marni, 2013).

Berdasarkan hasil penelitian secara deskripsif dengan responden sebanyak 112 siswa SMA Negeri 2 Kota Palangka Raya diperoleh paling banyak berjenis kelamin laki-laki sebanyak 60 responden (53,57\%). Pekerjaan orang tua responden paling banyak adalah PNS sebanyak 35 responden (31,25\%). Berdasarkan jarak rumah ke sekolah, paling banyak sekitar 3-5 km sebanyak 43 responden (38,39\%). Untuk aktivitas fisik paling banyak beraktivitas sedang sebanyak 75 responden $(66,96 \%)$ dan paling banyak berstatus gizi normal sebanyak 66 responden $(58,93 \%)$.

Selanjutnya dilakukan analisis bivariat pada variabel faktor aktivitas fisik terhadap status gizi siswa di SMA Negeri 2 Kota Palangaka Raya diperoleh hasil analisis regresi logistic menunjukkan nilai Pvalue 0,002 yang berarti bahwa faktor aktivitas fisik mempengaruhi 
status gizi remaja di SMA Negeri 2 Kota Palangka Raya. Untuk nilai OR (odds ratio) diperoleh 3,71 dengan CI 1,63 - 8,48. Ini bermakna bahwa dengan memiliki aktivitas fisik yang kurang baik berisiko 3,71 kali mengalami status gizi yang tidak normal dibandingkan memiliki aktivitas fisik yang baik.

Hasil penelitian ini relevan dengan Anggraini (2014) dengan judul hubungan tingkat aktivitas fisik terhadap status gizi pada anak usia prasekolah menyimpulkan bahwa terdapat hubungan yang signifikan antara aktivitas fisik dengan status gizi anak. Penelitian ini terdapat perbedaan yang bermakna antara waktu tidur, sedentary dan kegiatan aktif terhadap anak dengan status gizi normal dan anak dengan status gizi berlebih.

Afrilia dan Festilia (2018) juga menyimpulkan bahwa ada hubungan antara aktivitas fisik dengan status gizi siswa dengan nilai Pvalue 0,021. Aktivitas fisik cukup dapat mencegah obesitas pada siswa.

\section{SIMPULAN}

Kesimpulan penelitian ini adalah faktor aktivitas fisik mempengaruhi status gizi siswa, dengan memiliki aktivitas fisik yang kurang baik berisiko mengalami status gizi yang tidak baik normal sebesar 3,71 kali dibanding yang memiliki aktivitas fisik yang baik.

\section{REFERENSI}

1. Adityawarman. 2007. Hubungan Aktivitas Fisik dengan Komposisi Tubuh pada Remaja. Semarang: Universitas Diponegoro.

2. Afrilia, Dwi Ayu dan Festilia, Shelly. 2018. Hubungan Pola Makan dan Aktivitas Fisik Terhadap Status Gizi di Siswa SMP Al-Azhar Pontianak. Pontianak Nutrition Journal (PNJ), Vol 01 No. 01 Tahun 2018.

3. Almatsier, S. 2004. Prinsip Dasar Ilmu Gizi. Jakarta: Gramedia Pustaka Utama.

4. Anggraini, Lonia dan Mexitalia, Maria. 2014. Hubungan tingkat Aktivitas Fisik Terhadap Status Gizi pada Anak Usia Prasekolah. Jurnal Kedokteran Diponegoro: http://www.neliti.com/publications/115667/hubungan-tingkat-aktivitas-fisik-terhadapstatus-gizi-pada-anak-usia-prasekolah, diakses pada tanggal 12 Desemeber 2018. 
5. Arisman. 2009. Gizi dalam Daur Kehidupan. Jakarta: Penerbit Buku Kedokteran EGC.

6. Kemenkes RI, 2011. Standar Antropometri Penilaian Status Gizi Anak. Dirjen Bina Gizi dan Kesehatan Ibu dan Anak: Direktorat Bina Gizi, Jakarta.

7. Kuriman, E. (2011). Pertumbuhan dan Perkembangan Jumlah Remaja. Bandung: STIKES Rajawali.

8. Marni. 2013. Gizi dalam Kesehatan Reproduksi. Yogyakarta: Pustaka Pelajar.

9. Notoatmodjo. 2010. Metodologi Penelitian Kesehatan. Jakarta: Rineka Cipta.

10. Proverawati, A. (2010). Obesitas dan Gangguan Perilaku Makan Remaja. Yogyakarta: Nuha Medika.

11. Proverawati, A. (2010). Permasalahan dan Perubahan Perilaku di Kehidupan Remaja. Yogyakarta: Nuha Medika.

12. Pudjiadi, S. (2005). Masalah Gizi dan Remaja. Jakarta: FKM UI.

13. Sulistyoningsih, H. 2012. Gizi untuk Kesehatan Ibu dan Anak. Jakarta: Graha Ilmu.

14. Sugiyono. 2007. Statistik untuk Penelitian. Bandung: CV. Alfabeta.

15. WHO. 2010. The World Health Report 2010. http://www.who.int/whr/2010/en/ index.html, diakses pada tanggal 18 Desember 2018. 